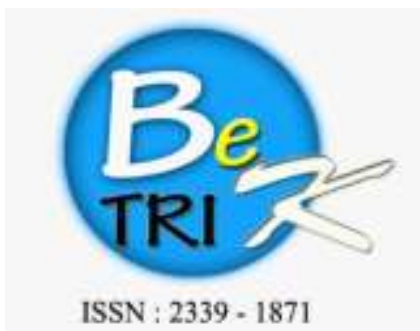
JURNAL ILMIAH BETRIK

Editor Office : LPPM Sekolah Tinggi Teknologi Pagar Alam, Jin. Masik Siagim No. 75 Simpang Mbacang. Pagar Alam, SUM-SEL, Indonesia Phone : +62 852-7901-1390.

Email : betrik@Ippmsttpagaralam.ac.id / admin.jumal@Ippmsttpagaralam.ac.id Website : hrtps://ejournal./ppmstipagaralam.ac.id/index.php/betrik/index

\title{
PENERAPAN KALMAN FILTER PADA METODE TRILATERASI UNTUK PENINGKATAN AKURASI ESTIMASI PERHITUNGAN JARAK DI DALAM RUANGAN
}

\author{
Fahrudin Mukti Wibowo', Auliya Burhanuddin² \\ Program Studi Informatika Institut Teknologi Telkom Purwokerto ${ }^{12}$ \\ Jl. D.I Panjaitan No. 128 Purwokerto, Jawa Tengah \\ Sur-el : fahrudin@ittelkom-pwt.ac.id ${ }^{1}$, auliya@ittelkom-pwt.ac.id ${ }^{2}$
}

\begin{abstract}
Abstrak: Penelitian tentang posisi maupun jarak suatu obyek di dalam ruangan telah banyak dilakukan. Metode trilaterasi adalah salah satu metode yang dapat dipergunakan untuk menghitung nilai estimasi jarak atau posisi suatu obyek di dalam ruangan, berdasarkan nilai RSSI (Received Signal Strength Indication) yang diterima suatu receiver. Namun, nilai RSSI yang diterima tidak dapat stabil dikarenakan sinyal yang diterima oleh receiver sangat dipengaruhi kondisi lingkungan pada ruangan yang pada umumnya memiliki nilai noise yang cukup tinggi. Sehingga dapat berakibat pada nilai estimasi jarak yang diperoleh menjadi kurang akurat. Sehubungan dengan hal tersebut maka setelah dilakukan perhitungan dengan trilaterasi, dilanjutkan dengan menambahkan metode Kalman Filter untuk meningkatkan nilai akurasi. Penelitian ini menggunakan BLE (Bluetooth Low Energy) sebagai transmitter, sedangkan receiver menggunakan smartphone yang sudah ter-install aplikasi untuk menerima nilai RSSI. Setelah menggunakan Kalman Filter diperoleh peningkatan nilai akurasi sebesar 0, 1 meter dari nilai perhitungan trilaterasi.
\end{abstract}

Kunci Utama: Trilaterasi, RSSI, BLE, Kalman Filter

\begin{abstract}
Research on the position and distance of an object in the room has been done. Trilateration method is one method that can be used to calculate the estimated value of the distance or position of an object in the room, based on the RSSI (Received Signal Strength Indication) value received by a receiver. However, the value of RSSI received can not be stable because the signal received by the receiver is greatly influenced by environmental conditions in the room which generally has a high enough noise value. So it can result in the estimated value of distance obtained to be less accurate. In relation to that then after calculations done by trilateration, followed by adding Kalman Filter method to increase the accuracy value. This research uses BLE (Bluetooth Low Energy) as a transmitter, whereas receivers use smartphones that have already installed applications to receive RSSI value. After using Kalman Filter obtained an increase of accuracy value 0, 1 meter of trilateration calculation value.
\end{abstract}

Keywords : Trilateration, RSSI, BLE, Kalman Filter

\section{PENDAHULUAN}

Teknologi informasi adalah hal yang terus berkembang, baik dari aspek software (perangkat lunak) berupa program maupun aplikasi dan dari aspek hardware (perangkat keras). Kedua aspek tersebut menjadi hal yang penting saat ini untuk 
sarana alat bantu dalam memenuhi berbagai macam kepentingan manusia. Kebutuhan akan teknologi informasi tidak lagi menjadi hal yang dibutuhkan kalangan tertentu saja, tetapi sudah hamper menyeluruh ke setiap kalangan masyarakat.

Salah satu informasi yang dapat diperoleh dari perkembangan teknologi informasi adalah informasi tentang sautu posisi atau lokasi suatu obyek tertentu, yang dapat diketahui melalui smartphone yang sudah ter-install aplikasi tertentu. Pada lingkungan di luar ruangan (outdoor) misalnya untuk mengetahui suatu lokasi wilayah di permukaan bumi, maka dapat memanfaatkan teknologi GPS (Global Positioning System). Dengan teknologi tersebut akan dengan mudah melacak suatu posisi obyek melalui informasi posisi (koordinat), dan ditampilkan secara visual melalui suatu peta virtual. Namun GPS akan memberikan hasil yang buruk ketika digunakan untuk lingkungan tertutup atau di dalam ruangan, karena tambahan redaman (attenuation) dan pemblokiran sinyal yang disebabkan oleh bangunan dan bahan bangunan. (line of sight) (Xu, Chen, $\mathrm{Xu}, \& \mathrm{Ji}, 2015)$.

Permasalahan untuk lingkungan di dalam ruangan lebih kompleks dibandingkan dengan lingkungan di luar ruangan. Berbagai gangguan seperti dinding ruangan, benda-benda yang ada di dalam ruangan, dan manusia yang berada di dalam ruangan dapat mempengaruhi propagasi gelombang elektromagnetik yang dapat menurunkan akurasi posisi di dalam ruangan. Sehingga tingkat akurasi estimasi posisi di dalam ruangan menjadi permasalahan dalam IPS (Indoor Positioning System). Berbagai metode dan teknologi telah banyak digunakan untuk desain sebuah IPS seperti Infra Red (IR), Radio Frequency Identyfier (RFID), Wireless Local Area Networks (WLAN), bluetooth, sensor network, dan Ultra Wide Band (UWB). (AlAmmar et al., 2014). Klasifikasi teknologi pada Indoor Positioning System ditunjukkan pada Gamabar 1.

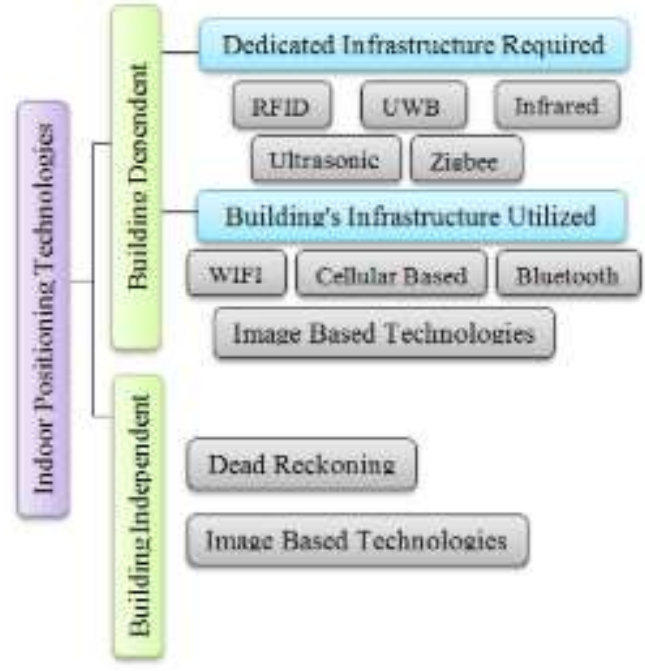

Gambar 1. Klasifikasi teknologi pada Indoor

Positioning (Al-Ammar et al., 2014)

Diantara berbagai macam teknologi pada indoor positioning, teknologi bluetooth merupakan teknologi yang membutuhkan infrastruktur dan biaya rendah. Perangkat teknologi bluetooth telah banyak tersedia cukup luas menyatu dengan suatu perangkat elektronik. Perkembangan teknologi bluetooth saat ini telah mencapai pada generasi 4.0 atau disebut BLE (Bluetooth Low Energy).(Faragher \& Harle, 2015)

BLE dibandingkan dengan generasi bluetooth sebelumnya adalah dirancang dengan konsumsi daya yang rendah dan jangkauan yang lebih luas. Daya yang rendah tersebut dapat dipenuhi oleh baterai smartphone yang saat ini berkembang di masyarakat. Selain dirancang menyatu dengan suatu perangkat elektronik, BLE 
juga diproduksi dalam kemasan terpisah. Salah satau produsen perangkat dengan memanfaatkan teknologi BLE adalah Apple yang disebut dengan iBeacon. Suatu modul iBeacon dapat memberikan berbagai informasi seperti Tx Power (kuat daya yang dipancarkan), RSSI (Received Signal Strenght Indicator) dan distance (jarak) yang dapat ditangkap oleh perangkat mobile.

Informasi yang diperoleh, selanjutya dapat diolah menggunakan metode tertentu untuk dimanfaatkan dalam estimasi jarak suatu obyek di dalam ruangan. Sehingga menegaskan bahwa teknologi BLE memiliki prospek yang baik dalam system localization di dalam ruangan. Pada BLE estimasi jarak adalah dengan memanfaatkan informasi nilai RSSI yang diterima. (Faragher \& Harle, 2015)

Metode trilaterasi merupakan metode yang umum digunakan dalam penentuan estimasi posisi suatu obyek di dalam ruangan. Metode ini mencari estimasi posisi berdasarkan referensi dengan jumlah minimal 3 titik referensi, sehingga ada yang menyebutnya dengan algoritme three border positioning. Namun, nilai akhir yang diperoleh masih memiliki nilai error sehingga diperlukan penambahan metode agar lebih meminimalkan error, salah satunya adalah dengan menambah metode Kalman Filter.

Penggunaan Kalman Filter pernah diteliti pada penerapan komunikasi menggunakan RFID (Radio Frequency Identification). Penelitian tersebut menyajikan penggunaan Kalman Filter untuk mengurangi kesalahan efek yang melekat pada sistem lokalisasi RFID. Hasil lokalisasi lebih akurat dalam lingkungan indoor.(Sanda, Abdel-Qader, \& Akanmu, 2014)
Pada paper ini, Kalman Filter digunakan untuk peningkatan akurasi estimasi jarak dari hasil estimasi jarak menggunakan metode trilaterasi. Data pengukuran dibatasi diambil di ruangan tanpa penghalang antara transmitter dengan receiver.

\section{METODE PENELITIAN}

\subsection{BLE (Bluetooth Low Energy)}

Perangkat modul BLE dapat berkomunikasi dengan perangkat mobile atau smartphone yang di dalamnya telah disertakan juga teknologi BLE. Selain itu harus memenuhi sistem operasi yang sudah dipersyaratkan. Jika perangkat mobile yang digunakan sebagai receiver merupakan produk dari Apple maka iBeacon hanya bisa dibaca oleh device dengan iOS versi 7 atau versi di atasnya. Jika perangkat mobile yang digunakan sebagai receiver berbasis Android maka hanya bisa dibaca oleh OS versi 4.3 (Jelly Bean) atau di atasnya.(Köhne \& Sieck, 2014). Salah satu fitur BLE adalah memiliki braodcast advertising mode yaitu kemampuan broadcast atau memberikan informasi ke perangkat yang berada di dekat BLE tersebut.

Berdasarkan kemampuan broadcast suatu BLE memiliki beberapa pembagian wilayah berdasarkan jangkauannya, yaitu immediate (antara iBeacon dengan receiver mempunyai jarak 0,5 meter), near (antara 1-2 meter), far (mempunyai jarak 30 meter) dan unknown (tidak diketahui) yaitu jarak lebih dari 30 meter seperti ditunjukkan pada Gambar 2.(Koühne \& Sieck, 2014). 
RSSI (Signal strength) is used to calculate which distance

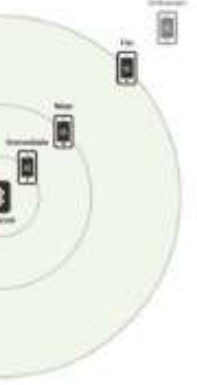

Four distance groups: Unknown: over $30 \mathrm{M}$

Far: within $30 \mathrm{M}$

Near: within $2 M$

Immediate: within $0.5 \mathrm{M}$

\section{Gambar 2. Wilayah Jangkauan pada iBeacon}

(Koühne \& Sieck, 2014)

\subsection{Metode Trilaterasi}

Metode trilaterasi adalah metode mencari estimasi posisi berdasarkan referensi dengan jumlah minimal 3 titik referensi yang sudah ditentukan. Metode trilaterasi dapat diilustrasikan pada Gambar 3. Titik perpotongan ketiga transmitter menunjukkan posisi receiver.

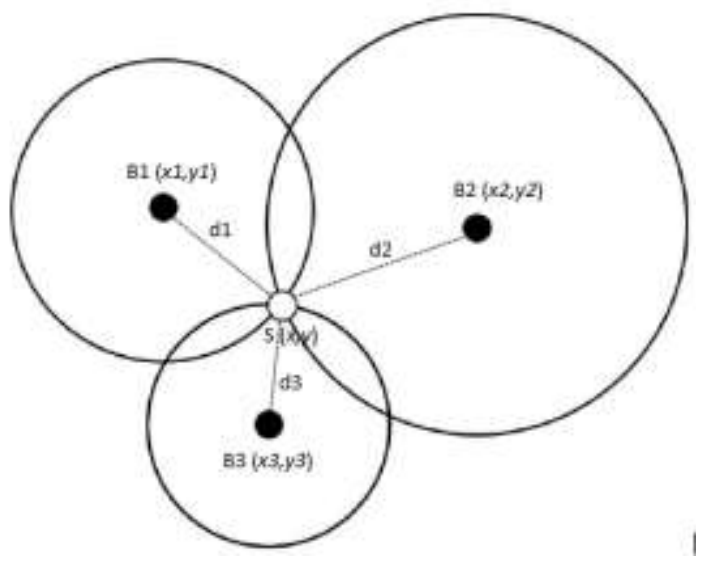

\section{Gambar 3. Metode Trilaterasi}

Nilai radius atau distance $(d)$ dapat dihitung dengan menggunakan persaman (1). (Wang, Yang, Zhao, Liu, \& Cuthbert, 2013) :

$$
\left(x-x_{\mathrm{i}}\right)^{2}+\left(y-y_{\mathrm{i}}\right)^{2}=d_{i}^{2}
$$

dengan:

$x_{\mathrm{i}} y_{\mathrm{i}}=$ koordinat titik transmitter

$x y=$ koordinat titik receiver sebenarnya

$d_{\mathrm{i}}=$ jarak transmitter dengan receiver

\subsection{Kalman Filter}

Metode Kalman filter merupakan suatu metode yang dapat dipergunakan untuk mengestimasi suatu variabel state dengan cara memodelkan sistem tersebut terlebih dahulu. Pada proses yang terjadi akan mengestimasi nilai dengan memfilter nilai tersebut untuk menghasilkan estimasi yang mendekati nilai sebenarnya. Pengolahan dalam Kalman Filter dapat dibagi menjadi dua fase utama, yaitu predict phase (fase prediksi) dan update phase (fase pembaruan). Selama fase prediksi algoritma memprediksi sampel baru berdasarkan sampel sebelumnya. Selama fase pembaruan filter menyaring perkiraan ini berdasarkan sampel baru dari sistem. Persamaan untuk setiap fase ditunjukkan pada persamaan berikut: (Sanda et al., 2014)

- fase prediksi

$$
\begin{aligned}
& \hat{x}_{k}^{-}=A \hat{x}_{k-1}+B u_{k-1} \\
& P_{k}^{-}=A P_{k-1} A^{T}+Q
\end{aligned}
$$

- fase pembaruan

$$
\begin{aligned}
K_{k} & =P_{k}^{-} H^{T}\left(H P_{k}^{-} H^{T}+R\right)^{-1} \\
\hat{x}_{k} & =\hat{x}_{k}^{-}+K_{k}\left(z_{k}-H \hat{x}_{k}^{-}\right) \\
P_{k} & =\left(I-K_{k} H\right) P_{k}^{-}
\end{aligned}
$$

\subsection{Rancangan Penelitian}

Data dalam penelitian ini diambil pada ruangan tanpa berpenghalang dengan ukuran \pm $5,72 \times 4,72 \mathrm{~m}^{2}$, kemudian lokasi penelitian tersebut dipetakan dalam bentuk koordinat. Jumlah titik referensi yang dipergunakan adalah tiga buah iBeacon dengan posisi tertentu yang difungsikan sebagai transmitter. Sedangkan untuk titik-titik posisi smartphone ditentukan pada 15 posisi yang berbeda yang difungsikan sebagai receiver. Model penentuan posisi tiga titik iBeacon dan titik pengukuran smartphone 
ditunjukkan pada Kesalahan! Sumber referensi tidak ditemukan.

Penempatan iBeacon adalah ditempel pada dinding ruangan dengan ketinggian \pm 2 meter dari lantai, hal tersebut sebagai gambaran skenario jika nantinya penelitian ini akan diterapkan pada kondisi sesungguhnya yaitu posisi tersebut tidak mengganggu aktifitas manusia yang berada pada ruangan tersebut dan dapat memperoleh kondisi line of sight). Sedangkan untuk penempatan smartphone, yaitu dengan ditaruh pada suatu alat dudukan (tripod).

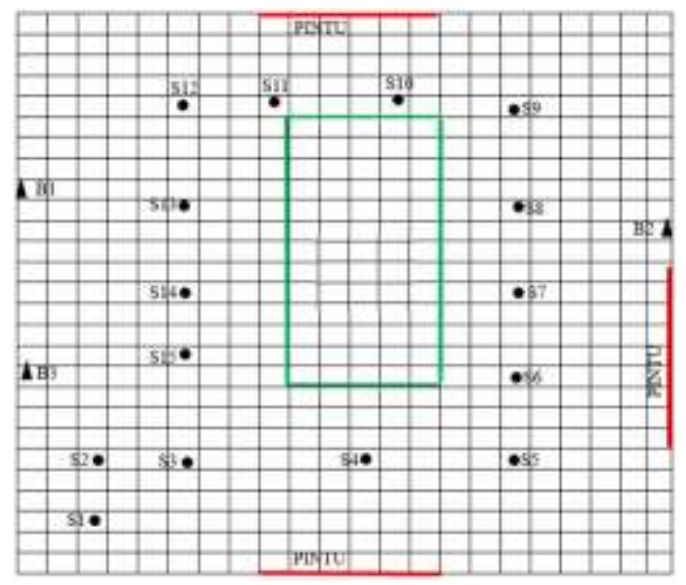

\section{Gambar 4. Denah Ruang Penelitian}

Pengukuran nilai distance dilakukan melalui aplikasi Bluetooth LE Scanner yang sudah diinstall pada smartphone. Nilai pengukuran distance yang dimiliki iBeacon (B) dinotasikan dengan $d$. Untuk memperoleh nilai pengukuran yang stabil, data pengukuran untuk setiap iBeacon dilakukan selama minimal 20 detik atau sampai ditunjukkan pengukuran dengan nilai yang stabil (Gambar 5).

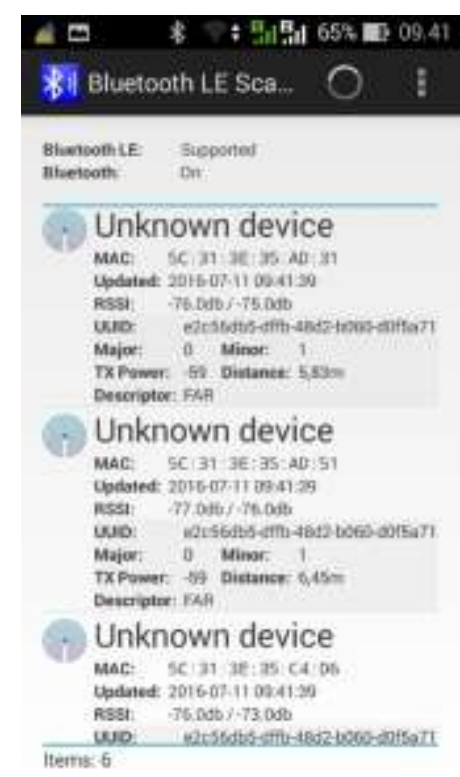

Gambar 5 Tampilan aplikasi Bluetooth LE Scanner

Dalam menganalisa perhitungan adalah yang pertama menggunakan metode perhitungan trilaterasi, yaitu dibuktikan dengan mencari error nilai posisi hasil perhitungan terhadap posisi sebenarnya. Kedua adalah dengan menerapkan Kalman Filter pada nilai hasil trilaterasi, kemudaian dicari nilai error seperti pada tahap analisa pertama. Berdasarkan kedua hasil pengujian akan diketahui apakah akurasi yang diperoleh akan meningkat atau tidak setelah diterapkan metode Kalman filter.

\section{HASIL DAN PEMBAHSAN}

\subsection{Hasil Pengukuran}

Sesuai dengan skenario pengujian maka pengukuran dilakukan dengan menggunakan aplikasi Bluetooth LE Scanner yang diinstall pada smartphone. Kemudian nilai parameter distance dicari tingkat kesalahan (error) yang terjadi terhadap nilai posisi sebenarnya. Langkah selanjutnya adalah dengan menggunakan Kalman Filter, untuk dicari tingkat kesalahan yang terjadi. Hasil perhitungan error ditunjukkan pada Tabel 1. 
Tabel 1. Hasil Error

\begin{tabular}{ccc}
\hline Posisi ke- & $\begin{array}{c}\text { Trilaterasi } \\
\text { (meter) }\end{array}$ & $\begin{array}{c}\text { Kalman Filter } \\
\text { (meter) }\end{array}$ \\
\hline 1 & 0,27 & 0,27 \\
\hline 2 & 0,14 & 0,14 \\
\hline 3 & 1,03 & 0,63 \\
\hline 4 & 1,12 & 0,76 \\
\hline 5 & 0,16 & 0,88 \\
\hline 6 & 2,01 & 0,98 \\
\hline 7 & 1,97 & 1,34 \\
\hline 8 & 0,93 & 1,25 \\
\hline 9 & 1,39 & 1,51 \\
\hline 10 & 0,67 & 0,83 \\
\hline 11 & 0,54 & 0,34 \\
\hline 12 & 0,05 & 0,14 \\
\hline 13 & 0,22 & 0,08 \\
\hline 14 & 0,09 & 0,27 \\
\hline 15 & 0,50 & 0,75 \\
\hline
\end{tabular}

Error

Rata-rata

Dari table 1 pengukuran di atas,

diperoleh nilai rata-rata error ketika hanya menggunakan metode trilaterasi adalah sebesar 0,7 meter sedangkan setelah dengan menambahkan metode Kalman Filter diperoleh nilai error sebesar 0,6 meter. Sehingga terjadi peningkatan akurasi sebesar 0,1 meter. Jika dilihat dari nilai peningkatan yang tidak terlalu besar, adalah dikarenakan pada proses perhitungan Kalman Filter pada penelitian, nilai noise diabaikan.

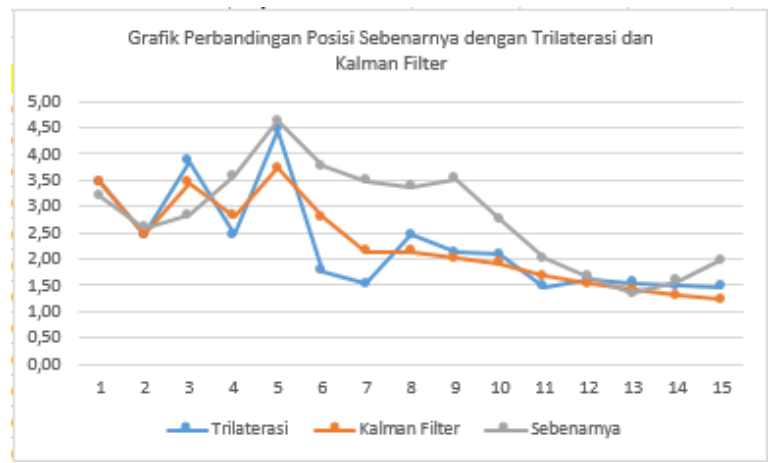

Gambar 6. Grafik Perbandingan
Pada Gambar 6, kami memperlihatkan perbandingan antara jarak sebenarnya dari suatu Smartphone terhadap iBeacon di lokasi penelitian, terhadap jarak hasil dari perhitungan menggunakan trilaterasi dan Kalman Filter. Penambahan metode Kalman Filter yang diimplementasikan berhasil memperbaiki kesalahan akurasi estimasi sebesar 0,1 meter.

\section{SIMPULAN}

Berdasarkan hasil pengamatan yang telah dilakukan maka dapat diambil kesimpulan metode Kalman Filter dapat dimanfaatkan untuk meningkatakan nilai akurasi estimasi jarak pada perhitungan menggunakan trilaterasi. Agar memperoleh nilai RSSI yang baik adalah pada jarak pengukuran 1 - 5 meter. Pada penelitian ini memperoleh nilai peningkatan akurasi sebesar 0,1 meter. Hal tersebut dapat dijadikan sebagai referensi ketika akan memilih metode yang tepat dalam mengembangkan suatu system estimasi jarak di dalam ruangan.

Penelitian dapat dikembangkan dengan mengukur nilai noise yang terjadi. Hal tersebut dapat lebih meningkatkan nilai akurasi pada metode Kalman filter. Sebab di dalam ruangan memiliki faktor penghalang seperti penempatan posisi iBeacon sebagai titik referensi, dan bendabenda yang terdapat di dalam ruangan yang dapat mengganggu sinyal yang diterima.

\section{DAFTAR RUJUKAN}

Al-Ammar, M. a., Alhadhrami, S., Al-Salman, A., Alarifi, A., Al-Khalifa, H. S., Alnafessah, A., \& Alsaleh, M. (2014). Comparative Survey of Indoor Positioning Technologies, Techniques, and Algorithms. 2014 
International Conference on Cyberworlds,

245-252.

https://doi.org/10.1109/CW.2014.41

Faragher, R., \& Harle, R. (2015). Location fingerprinting with bluetooth low energy beacons. IEEE Journal on Selected Areas in Communications, 33(11), 2418-2428. https://doi.org/10.1109/JSAC.2015.243028 1

Koühne, M., \& Sieck, J. (2014). Location-Based Services with iBeacon Technology. In 2014 2nd International Conference on Artificial Intelligence, Modelling and Simulation (AIMS) (pp. 315-321). https://doi.org/10.1109/AIMS.2014.58

Sanda, B., Abdel-Qader, I., \& Akanmu, A. (2014). Kalman filters for reducing error in RFID real-time localization systems. IEEE International Conference on Electro Information Technology, 324-329. https://doi.org/10.1109/EIT.2014.6871785 Wang, Y., Yang, X., Zhao, Y., Liu, Y., \& Cuthbert, L. (2013). Bluetooth positioning using RSSI and triangulation methods. 2013 IEEE 10th Consumer Communications and Networking Conference, CCNC 2013, 837842.

https://doi.org/10.1109/CCNC.2013.64885 58

Xu, R., Chen, W., Xu, Y., \& Ji, S. (2015). A New Indoor Positioning System Architecture Using GPS Signals. Sensors, 15(5), 1007410087. https://doi.org/10.3390/s150510074 